\title{
Pathoproteomics of testicular tissue deficient in the GARP component VPS54: The wobbler mouse model of globozoospermia
}

\author{
Harald Jockusch ${ }^{1}$, Ashling Holland ${ }^{2}$, Lisa Staunton ${ }^{2}$, Thomas Schmitt-John ${ }^{3}$, Peter Heimann ${ }^{4}$ \\ Paul Dowling ${ }^{5}$ and Kay Ohlendieck ${ }^{2}$ \\ ${ }^{1}$ Department of Developmental Biology and Molecular Pathology, University of Bielefeld, Bielefeld, Germany \\ ${ }^{2}$ Department of Biology, National University of Ireland, Maynooth, Ireland \\ ${ }^{3}$ Department of Molecular Biology and Genetics, Aarhus University, Aarhus, Denmark \\ ${ }^{4}$ Department of Cell Biology, University of Bielefeld, Bielefeld, Germany \\ ${ }^{5}$ National Institute for Cellular Biotechnology, Dublin City University, Dublin, Ireland
}

\begin{abstract}
In human globozoospermia, round-headed spermatozoa lack an acrosome and therefore cannot properly interact with oocytes. In the wobbler (WR) mouse, an L967Q missense mutation in the vesicular protein-sorting factor VPS54 causes motor neuron degeneration and globozoospermia. Although electron microscopy of WR testis shows all major components of spermatogenesis, they appear in a deranged morphology that prevents the formation of the acrosome. In order to determine proteome-wide changes, affected testes were analysed by 2D-DIGE and MS. The concentration of 8 proteins was increased and that of 35 proteins decreased as compared to wild type. Mass spectrometric analysis identified proteins with an altered concentration to be associated with metabolite transport, fatty acid metabolism, cellular interactions, microtubule assembly and stress response (chaperones Hsp70-2 and Hsp90 $\alpha$ ). Minor changes were observed for proteins involved in cell redox homeostasis, cytoskeleton formation, PTMs, detoxification and metabolism. The most dramatically decreased protein in WR testis was identified as fatty acid binding protein FABP3, as confirmed by immunoblot analysis. We conclude that a missense mutation in VPS54, an essential component of the Golgi-associated retrograde protein complex, not only prevents the formation of an acrosome but also initiates a cascade of metabolic abnormalities and a stress reaction.
\end{abstract}

\section{Keywords:}

Acrosome / Animal proteomics / Fatty acid binding protein / GARP complex / HSP / Spermatogenesis

Additional supporting information may be found in the online version of this article at the publisher's web-site

\section{Introduction}

The wobbler (genotype wr/wr, phenotype WR) mouse mutant [1] represents an established animal model of progressive

Correspondence: Prof. Kay Ohlendieck, Chair, Department of Biology, National University of Ireland, Maynooth, Co. Kildare, Ireland E-mail: kay.ohlendieck@nuim.ie Fax: $+353-1-708-3845$

Abbreviations: SOD, superoxide dismutase; VDAC, voltagedependent anion-selective channel protein; WR, wobbler; WT, wild type
Received: May 15, 2013

Revised: August 12, 2013 Accepted: September 10, 2013 neurodegeneration, as recently reviewed by Moser et al. [2]. On a C57BL/6J background, this phenotype is paralleled by distinct deficiencies in spermatogenesis $[3,4]$. The mutation wr maps to chromosome 11 [5] and has been identified as a missense mutation in the ubiquitously expressed gene Vps54 [6]. The Vps54 gene encodes vesicular protein-sorting factor VPS54 that is part of the hetero-tetrameric Golgi-associated retrograde protein (GARP) complex [7]. So far no human neurodegenerative disease has been identified in which the gene that encodes the VPS54 protein is affected [8]. The fact that VPS54 is associated with retrograde vesicle transport to the Golgi apparatus makes it an essential factor of intracellular 
transport mechanisms [7]. The recessive wr mutation leads to a leucine-to-glutamine replacement (L967Q) near the Cterminus of the 977 amino acid polypeptide chain [6]. This hydrophobic-to-hydrophilic exchange destabilises the tertiary structure and thereby leads to a reduction in the concentration of VPS54 [9]. A homozygous knockout of the Vps54 gene confers embryonic lethality [6]. However, the wr missense allele is relatively mild in that it allows homozygous animals to survive for several months, albeit with a rapidly developing muscular atrophy [2] and a defect in spermatogenesis $[3,4,10]$.

The abnormal density, motility or morphology of sperm cells plays a crucial role in infertility. The defect in sperm assembly in the WR mutant is associated with a failure to form an acrosome and an elongated sperm head $[3,4]$ resulting in an abnormality similar to globozoospermia in humans [11], whereby acrosome-less sperm heads are unable to penetrate the zona pellucida and thus cannot properly interact with the oocyte. Even intra-cytoplasmic sperm injection results often in fertilization failure due to a deficient activation capacity in oocytes [12]. In analogy, WR sperm cells show a roundheaded irregular morphology reminiscent of globozoospermia $[3,4,10]$, making the testis of this mouse mutant an ideal model to systematically study pathobiochemical aspects of this type of impaired spermatogenesis. It was previously shown that WR spermatids exhibit increased amounts of the mouse ubiquitin-specific processing protease mUBPy and differential sorting of this deubiquitinating enzyme [13]. In addition, the oocyte-activating factor phospholipase PLC-zeta has an abnormal localization in WR sperm cells with a reduced fertilizing capacity [14].

Molecular and cellular aspects of testis biology and the developmental process of spermatogenesis have been well documented and widely studied by cell biological and microscopical methods [15]. In contrast to cellular aspects of sperm development, the complexity of global changes in the protein constellation of the testis has not been well understood until the emergence of modern proteomics [16] as outlined in several reviews on sperm cell proteomics [17-21]. MS-based proteomics has shown the diversity of the catalogued proteome of spermatozoa from a variety of different species [22-26] and has been applied to the large-scale analysis of sperm head and flagella sub-compartments [27], sperm surface proteins [28], the epididymal maturation of mammalian spermatozoa [29], sperm capacitation [30-33], the effect of androgen manipulation during spermatogenesis [34], male gametes in relation to oxidative stress [35], sperm protein phosphorylation patterns [30,36] and sperm-oocyte interactions [37]. Thus, testis and sperm cell proteomics has a biomedical potential to identify novel protein markers of genetic abnormalities or the effects of environmental insults and disease factors that may be involved in male infertility [38-41].

Here, we have used gel electrophoresis based proteomics to investigate potential differences in protein expression levels between wild-type (WT) mouse testis and mutant WR testis. Fluorescence 2D-DIGE analysis was employed to separate the urea-soluble portion of the testis proteome and proteins with a changed concentration were identified by MS. The DIGE method represents one of the most powerful comparative techniques in protein biochemistry and enables the direct comparison of two different protein populations on the same high-resolution 2D gel system [42]. Gel electrophoretic analyses and proteomic approaches have previously been applied to the screening of WR tissues, i.e. spinal cord [43-45] and skeletal muscle [46], and used here for studying total extracts from normal versus affected testis tissue. Proteome-wide changes included proteins involved in metabolite transport, fatty acid metabolism, cellular interactions, microtubule assembly and the cellular stress response.

\section{Materials and methods}

\subsection{Materials and chemicals}

For the gel electrophoresis based proteomic profiling of testis tissue, ampholytes, cover fluid, ACN, IPG drystrips $\mathrm{pH} 3$ 10, CBB and CyDye DIGE Fluor minimal dyes Cy3 and Cy5 were purchased from Amersham Biosciences/GE Healthcare (Little Chalfont, Buckinghamshire, UK). Protease inhibitors were obtained from Roche Diagnostics (Mannheim, Germany). Acrylamide stock solutions were purchased as ultrapure Protogel from National Diagnostics (Atlanta, GA, USA). Laemmli-type buffer, protein molecular mass ladders and Bradford reagent for protein quantification were from Biorad Laboratories (Hemel-Hempstead, Hertfordshire, UK). For ingel protein digestion, sequencing grade-modified trypsin was obtained from Promega (Madison, WI, USA). Ultra-clean LCMS Chromasolv water and formic acid were purchased from Fluka (Milwaukee, WI, USA). Antibodies were from Abcam, Cambridge, UK (ab16916-1 to FABP3, ab43176 to ATP synthase, ab14734 to voltage-dependent anion-selective channel protein 1 (VDAC1), ab13533 to superoxide dismutase (SOD), ab2787 to Hsp70, ab13492 to Hsp90) and Chemicon International Temecula, CA, USA (secondary peroxidase-conjugated antibodies). Spin filters were obtained from Fisher Scientific (UK). Nitrocellulose transfer stacks were from Invitrogen (Carlsbad, CA, USA). Chemiluminescence substrate was purchased from Roche Diagnostics (Manheim, Germany). X-ray films were from Fuji Photo Film (Tokyo, Japan). Ultrapure lysine for quenching the DIGE labelling reaction and all general reagents were purchased from Sigma Chemical Company (Dorset, UK).

\subsection{Animals and tissues}

The stock carrying the $w r$ mutation on a C57BL/6J background were obtained in 1979 from Harvard Medical School $[5,6]$. Breeding of mice was carried out in the animal facilities of Bielefeld University and Aarhus University in accordance with German and Danish laws on the protection of laboratory animals and approved by the local authorities. Testes 
without epididymis were prepared from 9-wk-old WR mice and age-matched normal C57BL/6J mice. WR and WT mice had an average body weight of $9.6 \pm 1.6 \mathrm{~g}(n=9)$ and $23.2 \pm$ $3.0 \mathrm{~g}(n=5)$, respectively [46]. Mice were sacrificed by cervical dislocation and testes were quick-frozen in liquid nitrogen and stored at $-80^{\circ} \mathrm{C}$ prior to proteomic analyses.

\subsection{Preparation of testis extracts for proteomic analysis}

For the preparation of testis extracts, deep-frozen tissue samples were ground into a fine powder using pestle and mortar in the presence of liquid nitrogen. For proteomic profiling studies, equal amounts of WR and WT tissue (100 mg wet weight) were employed. Testis tissue powder was suspended in $1 \mathrm{~mL}$ of DIGE lysis buffer and then urea-soluble proteins extracted by a previously optimised method [47].

\subsection{D-DIGE analysis of WT testis extracts}

A fluorescence gel electrophoretic approach, as previously described in detail [46], has been used here for the comparative analysis of WR versus WT testis. For each biological repeat, $50 \mu \mathrm{g}$ of protein sample was pre-electrophoretically labeled with a fluorescent CyDye. Extracts from WR and WR testis were each labelled with Cy3 DIGE fluor dye. For internal standardization, pooled samples were labeled with Cy5 DIGE fluor dye. Quenching of the DIGE labelling reaction was performed with ultrapure lysine. The gel electrophoretic separation of CyDye-labeled proteins was carried out with a total amount of $100 \mu \mathrm{g}$ protein per analytical DIGE gel. Isoelectric focusing, equilibration with DTT, equilibration with iodoacetamide and slab gel electrophoresis were performed by standardised protocols [48]. Subsequently, the separated and fluorescently labeled proteins were visualised using a Typhoon Trio variable mode imager and changed protein abundances determined with Progenesis SameSpots analysis software from NonLinear Dynamics (Newcastle upon Tyne, $\mathrm{UK})$, using the following parameters: $n=4$, $t$-test $p<0.05$, and a power value $>0.8$. Testis-associated protein species that showed a significant difference in concentration in WR samples as compared to WT controls were picked for tryptic digestion from Coomassie Blue stained preparative gels [47].

\subsection{Mass spectrometric identification of testis proteins}

In order to generate representative peptide populations from proteins of interest, gel spots with identified proteins were excised, washed, destained and then treated with trypsin [48]. Peptide mixtures were dried through vacuum centrifugation and resuspended in MS-grade distilled water and $0.1 \% \mathrm{v} / \mathrm{v}$ formic acid, spun down through spin filter and added to
LC-MS vials for mass spectrometric identification. Sample separation was carried out with a nanoflow Agilent 1200 series system. Peptide mixtures were loaded into the enrichment at a capillary flow rate set to $2 \mu \mathrm{L} / \mathrm{min}$ with a mix of $0.1 \% \mathrm{v} / \mathrm{v}$ formic acid and $50 \% \mathrm{v} / \mathrm{v} \mathrm{ACN}$ and formic acid at a ratio of 19:1. The voltage was set to $1700 \mathrm{~V}$. MS analysis was carried out on a Model 6340 Ion Trap LC/MS apparatus from Agilent Technologies (Santa Clara, CA, USA). Database searches were performed with MASCOT MS/MS ion search (Matrix Science, London, UK; NCBI database, release 20100212) using Mus musculus as taxonomic category and the following parameters: (i) two missed cleavages by trypsin, (ii) mass tolerance of precursor ions $\pm 2.5 \mathrm{Da}$ and product ions $\pm 0.7 \mathrm{Da}$, (iii) carboxymethylated cysteins fixed modification, and (iv) oxidation of methionine as variable modification, and (v) at least two matched distinct peptides.

\subsection{Immunoblot analysis}

In order to verify changes in testis-associated proteins of interest, immunoblotting with antibodies against select testis proteins was used. WR and WT proteins were separated by $1 \mathrm{D}$ gel electrophoresis and transferred to nitrocellulose membranes [48]. Membrane sheets were blocked in a solution of fat-free milk protein for $1 \mathrm{~h}$ and incubated overnight with gentle agitation with antibodies, sufficiently diluted in blocking solution containing $5 \% \mathrm{w} / \mathrm{v}$ milk powder in PBS $(0.9 \% \mathrm{w} / \mathrm{v} \mathrm{NaCl}, 50 \mathrm{mM}$ sodium phosphate, $\mathrm{pH}$ 7.4). Nitrocellulose sheets were then washed with blocking solution twice for $10 \mathrm{~min}$ and blots incubated for $1 \mathrm{~h}$ with secondary peroxidase-conjugated antibodies diluted in blocking solution. Visualization of antibody-decorated bands was performed with the ECL method following the manufacturer's recommendations. Densitometric scanning of immunoblots was performed on a Molecular Dynamics 300S computing densitometer (Sunnyvale, CA, USA) with Imagequant V3.0 software.

\subsection{Bioinformatics analysis of potential protein interactions}

Bioinformatics software was applied to identify potential protein interactions and the clustering of molecular functions of the mass spectrometrically identified proteins with a changed abundance in WR testis. Analyses were performed with (i) the STRING (http://string-db.org/, version 9.1) database of known and predicted protein interactions that include direct physical and indirect functional protein associations [49], (ii) the IntAct (http://www.ebi.ac.uk/intact, version 4.1) molecular interaction database that is populated by data either curated from the literature or from direct data depositions [50] and (iii) the PANTHER (http://pantherdb.org, version 8.1) comprehensive database of protein families for the cataloguing of molecular functions [51]. 


\subsection{Electron microscopy}

Samples of tissue for transmission electron microscopy were prepared as previously described in detail [4]. Spermatozoa for scanning electron microscopy were obtained from the epididymis, fixed by standard procedures, and critical point dried, Au-sputtered and examined in a Hitachi scanning electron microscope.

\section{Results}

\subsection{Ultra-structural analysis of WR testicular tissue}

Fluorescence and electron microscopy has revealed that the most conspicuous feature in WR spermatogenesis is the failure to form an intact acrosome by fusion of pro-acrosomal Golgi-derived vesicles, the association of an acrosome with the nucleus and the flattening into an eagle-beak-like structure [4], as confirmed by Paiardi et al. [10]. The development and formation of WR spermatozoa within the testis has previously been described in detail [4]. Mature spermatozoa from the epididymis are shown in Fig. 1. Intact WT spermatozoa show the typical zoning into a head structure (with highly condensed nucleus and acrosome) and sperm tail with a mid piece (characterised by tightly packed mitochondria), a principal and an end piece (Fig. 1A). In contrast, the hallmark of WR spermatozoa is an irregularly rounded head containing a strongly deformed (often bizarre and fragmented) nucleus of usually heterogeneous density and lacking an acrosome (Fig. 1B and C). Often the zoning into head and mid piece is incomplete, and head and mid piece are combined either into one globular region (Fig. 1B) or the elongation and allocation process is faulty and all mitochondria remain in the head region, though a shortened mid piece is developed (Fig. 1C). Despite some spermatozoa displaying an intact morphology within the principal piece, most spermatozoa show aberrations in the $9 \times 2+2$ axoneme structure [3], as well as in presence, number and size of the outer dense fibres (Fig. 1D). While the cell membrane is missing to a large extent, the fibrous sheath of the principal piece, as the sole component, seems not to be altered in the WR mouse (Fig. 1D). In view of these detailed morphological findings, more information on the pathogenesis in WR testis could be expected from the execution of complementary biochemical analyses of global protein changes.

\subsection{Proteomic profiling of normal mouse testis}

The fluorescence 2D-DIGE technique is capable of detecting changes in a wide range of protein concentrations [42], making this comparative method an ideal analytical tool to study proteome-wide alterations in the WR mutant. Prior to the proteomic profiling of WT versus WR testis preparations, the protein constellation of normal mouse
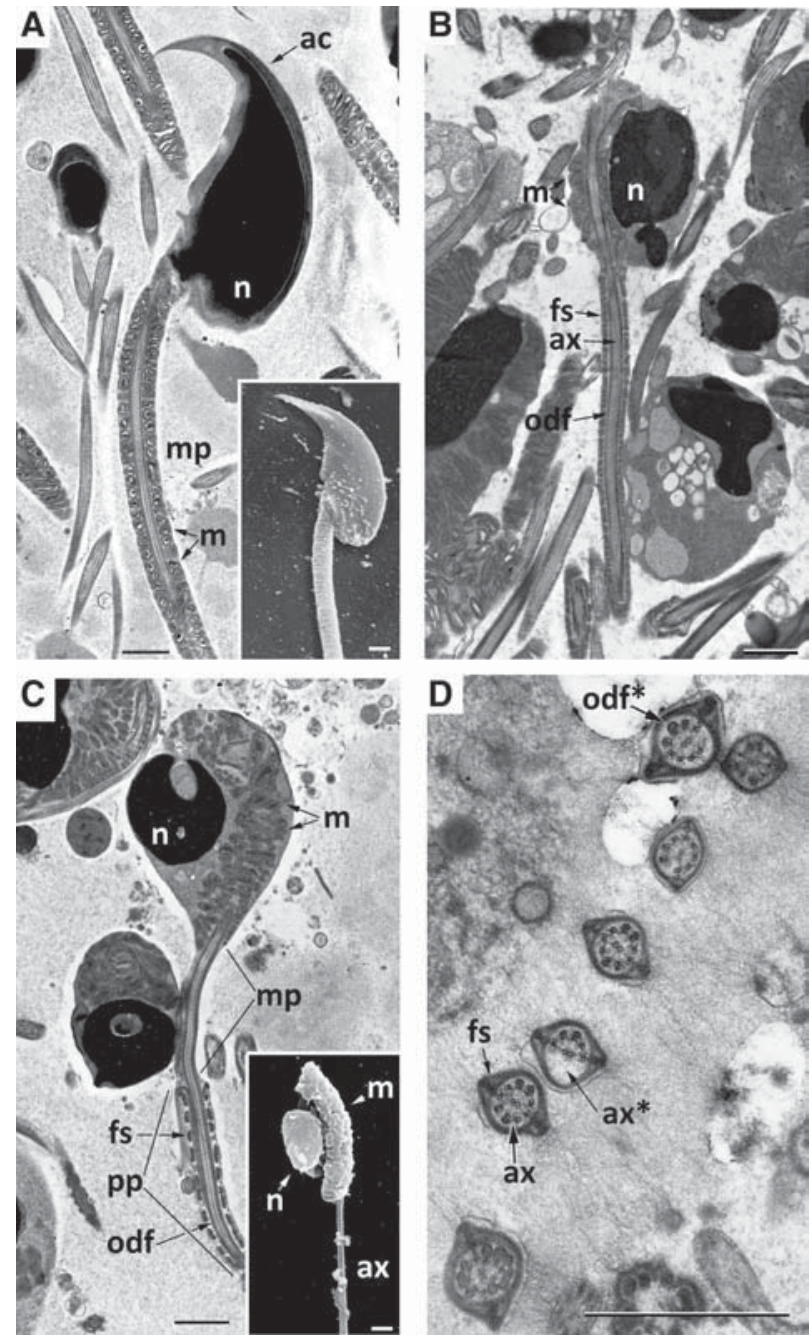

Figure 1. Defective spermatogenesis in the WR mouse: fine structure of spermatozoa. (A) WT, (B, C, D) WR. Main panels: Transmission electron microscopy of ultra-thin sections through epididymis, Insets: scanning electron microscopy of isolated spermatozoa. (A) Mature WT spermatozoon shows typical zoning into head (with highly condensed nucleus and acrosome) and tail with mid piece (characterized by tightly packed mitochondria) and (not shown) principal and end piece (sagittal section). Inset in (A): spermatozoon head and mid piece region. ( $B, C)$ WR spermatozoa display an irregularly rounded shape of head with a strongly deformed and fragmented nucleus. There is no acrosome. Often the zoning into head and mid piece is incomplete and head and midpiece are combined either into one globular region $(B)$ or the elongation and allocation process is faulty and all mitochondria remain in the head region, though a shortened midpiece lacking mitochondria (C). Inset in (C): isolated spermatozoon with midpiece region (with mitochondria) attached to the head (with nucleus). (D) Although some WR spermatozoa display an intact morphology within the principal piece, most WR spermatozoa show aberrations in the $9 \times 2+2$ axoneme structure $\left(a x^{*}\right)$, as well as in presence, numbers and size of the outer dense fibres (odf*). The fibrous sheath of the principal piece seems not to be altered. ac, acrosome; ax, axoneme; fs, fibrous sheath; m, mitochondria; $\mathrm{mp}$, midpiece; $\mathrm{n}$, nucleus; odf, outer dense fibber; $\mathrm{pp}$, principal piece. All scale bars $-1 \mu \mathrm{m}$. 


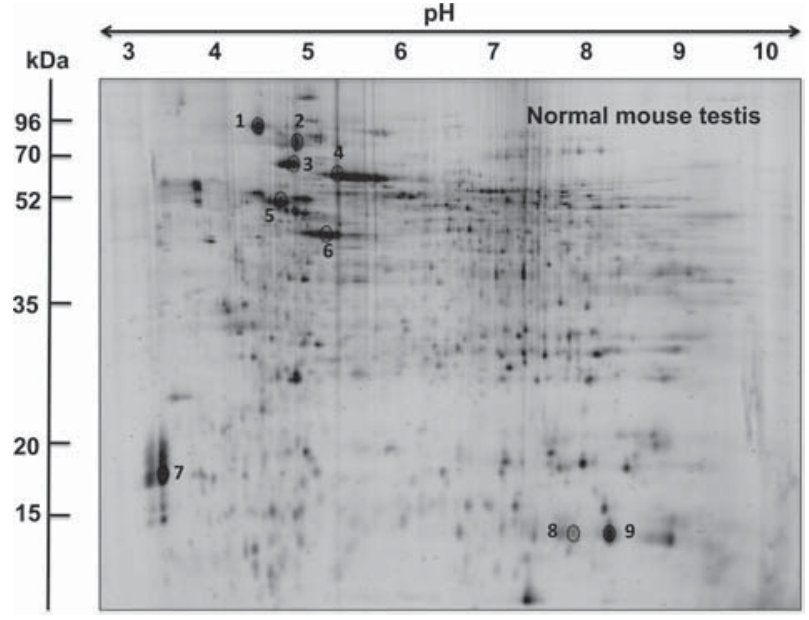

Figure 2. 2DE analysis of WT testis. Shown is a $2 \mathrm{D}$ gel of total extracts from 9-wk-old mouse testis. Major protein spots are marked by circles and are numbered 1 to 9 . See Table 1 for the mass spectrometric identification of $2 \mathrm{D}$ landmark proteins that are not changed in the WR model of globozoospermia. The $\mathrm{pH}$ values of the first dimension gel system and molecular mass standards (in kilodalton) of the second dimension are indicated on the top and on the left of the panel, respectively.

testis was evaluated by gel electrophoresis and major protein species identified by MS. Since fluorescence DIGE-based investigations can swiftly assess potential concentration changes in thousands of protein spots, it was advantageous to establish a select number of reliable and unchanged 2D landmark protein spots for control purposes. Gel electrophoretic approaches using isoelectric focusing in the first dimension and polyacrylamide slab gel electrophoresis in the second dimension separate highly efficiently the urea-soluble subproteome from crude tissue extracts. A representative proteomic map is shown in Fig. 2 to illustrate the general distribution pattern of testis-associated proteins, based on their unique combinations of isoelectric point and molecular mass.
Abundant constituents were picked from gels, digested with trypsin and then identified by MS. The identified marker proteins covered a $\mathrm{p} I$ range from $\mathrm{p} I 4.74$ to 7.96 and ranged in apparent molecular mass from 15.1 to $92.7 \mathrm{kDa}$ (spot 1, endoplasmin; spot 9, haemoglobin). Table 1 lists identified testis marker proteins, their protein accession number, isoelectric point, molecular mass, MASCOT score, percentage sequence coverage and number of matched peptide sequences. Spots 1 to 9 represent major testis proteins with isoelectric point to molecular mass combinations of approximately $\mathrm{pI} 4.74 / 92.7$ $\mathrm{kDa}, \mathrm{p} I$ 4.93/85.1 kDa, pI 5.07/72.5 kDa, pI 5.51/69.9 kDa, pI $4.82 / 50.9 \mathrm{kDa}, \mathrm{p} I 5.56 / 41.3 \mathrm{kDa}, \mathrm{p} I 4.09 / 16.7 \mathrm{kDa}, \mathrm{p} I$ $7.14 / 15.8 \mathrm{kDa}$ and $\mathrm{p} I 7.96 / 15.1 \mathrm{kDa}$, respectively. The mass spectrometric analysis of their respective peptide populations revealed the presence of specific isoforms of endoplasmin, HSP Hsp90, 78-kDa glucose-regulated protein, tubulin, actin, calmodulin, $\beta$-globin and $\alpha$-globin, respectively, in these major unchanged 2D protein spots (Table 1). The presence of haemoglobin reflects the fact that the animals had not been perfused prior to sacrificing, and that the WR and WT tissues were equally well vascularised.

\subsection{Comparative proteomic analysis of WR versus WT testis}

Following the initial mass spectrometric identification of testis marker proteins from normal control mice, pre-electrophoretic fluorescent tagging and subsequent comparative high-resolution 2DE was carried out. Figure 3 gives an overview of the DIGE gels used in this study and illustrates the images received with CyDye Cy3 labelling of mutant testis (WR) and WT testis (WT), as well as CyDye Cy5 labelling of pooled standards. For image analysis and densitometric scanning, four biological repeats were used, which resulted in mutant samples Cy3 WR1 to WR4 and pooled controls Cy5 WR1 to WR4, as well as WT samples Cy3 WT1 to WT4 and pooled controls Cy5 WT1 to WT4. Densitometric scanning revealed significant changes in 43 testis-associated proteins.

Table 1. MS-identified 2D landmark proteins from mouse testis tissue

\begin{tabular}{|c|c|c|c|c|c|c|c|}
\hline Spot no. & Identified protein & Accession no. & $\mathrm{p} /$ & $\begin{array}{l}\text { Molecular } \\
\text { mass (kDa) }\end{array}$ & $\begin{array}{l}\text { MASCOT } \\
\text { score }\end{array}$ & $\begin{array}{l}\text { Coverage } \\
(\%)\end{array}$ & $\begin{array}{l}\text { Peptides } \\
\text { matched }\end{array}$ \\
\hline 1 & Endoplasmin GRP94 & gi|6755863 & 4.74 & 92708 & 986 & 44 & 37 \\
\hline 2 & Hsp 90-alpha & gi|6754254 & 4.93 & 85141 & 377 & 35 & 27 \\
\hline 3 & 78-kDa glucose-regulated protein & gi|254540166 & 5.07 & 72493 & 778 & 48 & 29 \\
\hline 4 & Heat shock related $70-k D a$ protein 2 & gi|31560686 & 5.51 & 69889 & 390 & 42 & 23 \\
\hline 5 & Tubulin, beta-3 chain & gi|12963615 & 4.82 & 50850 & 295 & 34 & 14 \\
\hline 6 & Actin, gamma & gi|809561 & 5.56 & 41340 & 243 & 52 & 16 \\
\hline 7 & Calmodulin & gi|71664 & 4.09 & 16696 & 219 & 52 & 10 \\
\hline 8 & Haemoglobin subunit beta & gi|156257625 & 7.14 & 15769 & 467 & 56 & 7 \\
\hline 9 & Haemoglobin subunit alpha & gi|122441 & 7.96 & 15134 & 163 & 50 & 7 \\
\hline
\end{tabular}

The table lists major 2D protein spots with an unchanged concentration in WR versus WT testicular tissue preparations. The haemoglobin spots 8 and 9 are due to the fact that testis preparations were not perfused prior to quick freezing in liquid nitrogen. 


\section{WR Testis}

Cy3 WR1

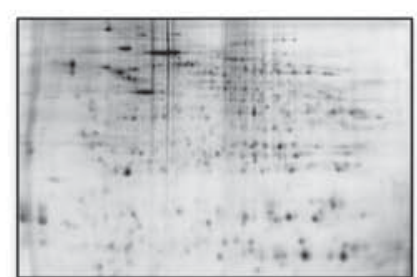

Cy3 WR2

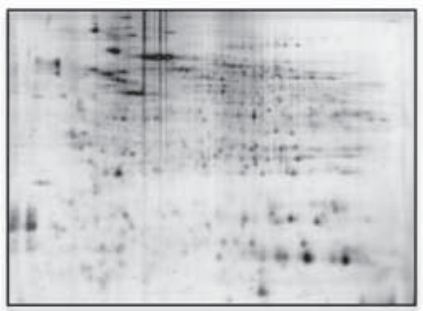

Cy3 WR3

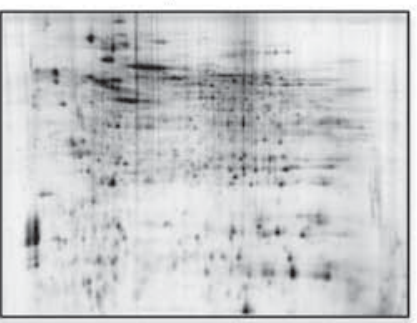

Cy3 WR4

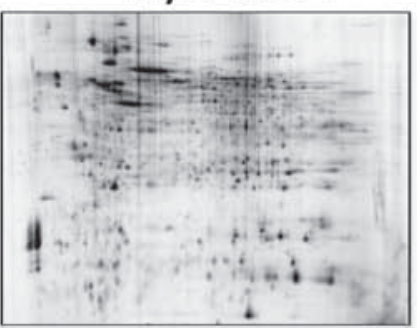

Pooled standard

Cy5 WR1

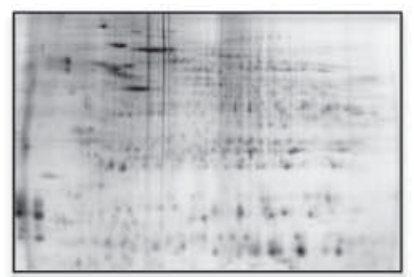

Cy5 WR2

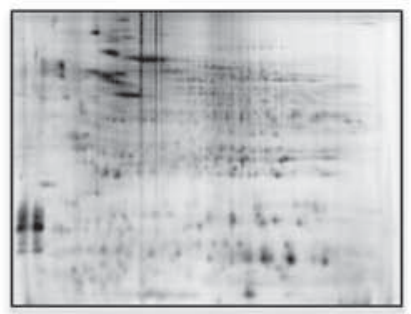

Cy5 WR3

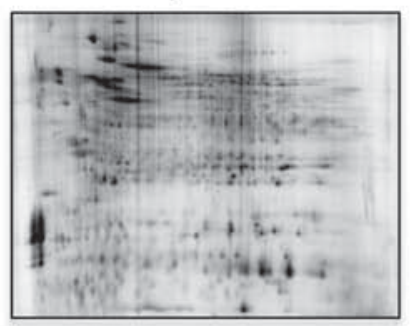

Cy5 WR4

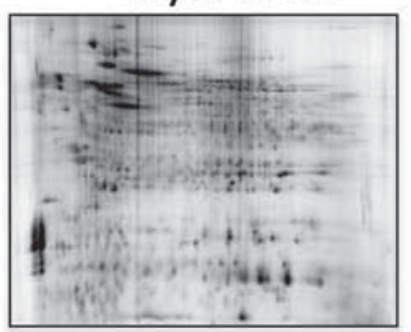

WT Testis

Cy3 WT1

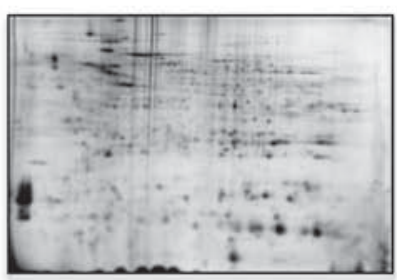

Cy3 WT2

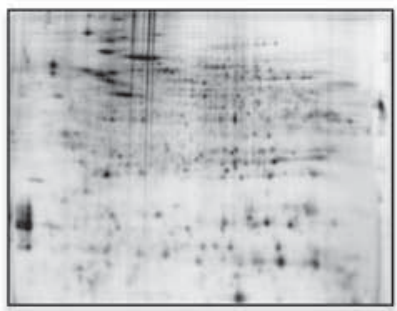

Cy3 WT3

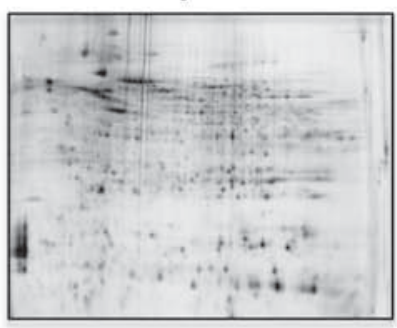

Cy3 WT4

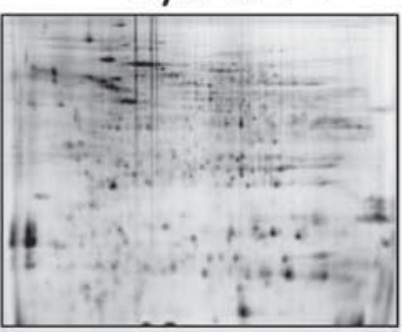

Pooled

standard

Cy5 WT1

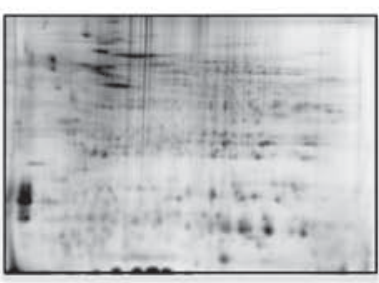

Cy5 WT2

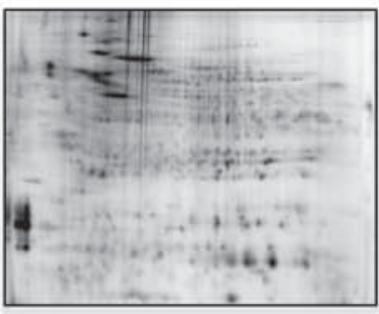

Cy5 WT3

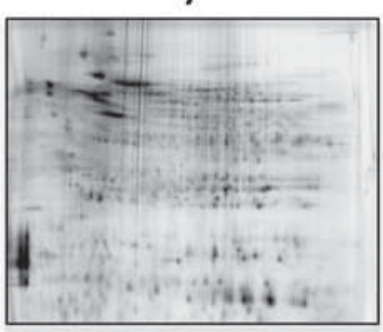

Cy5 WT4

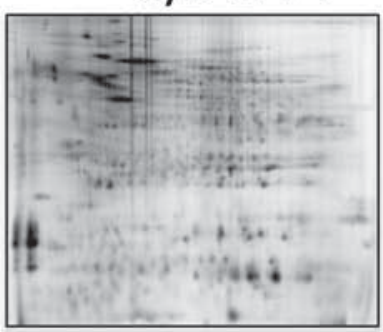

Figure 3. 2D-DIGE analysis of WR versus normal testis tissue. Shown are Cy3-labelled gels of total testis extracts from WR (WR1 to WR4) versus normal WT (WT1 to WT4) mice, as well as Cy5-labelled gels containing pooled standards. DIGE images are shown for the pH 3-10 range.

\subsection{Mass spectrometric identification of changed proteins in WR testis}

A CyDye-labelled 2D master gel of WR testis is shown in Fig. 4, covering a $\mathrm{pH}$ 3-10 range. An altered concentration of proteins in WR testis included components in 2D spots that ranged in molecular mass from approximately $14.8 \mathrm{kDa}$ (fatty acid binding protein FABP3, spot 1) to $85.1 \mathrm{kDa}$ (HSP Hsp90, spot 43) and covered a $\mathrm{p} I$ range from approximately 4.79 (tubulin, spot 5) to 10.36 (spermatid-specific protein, 


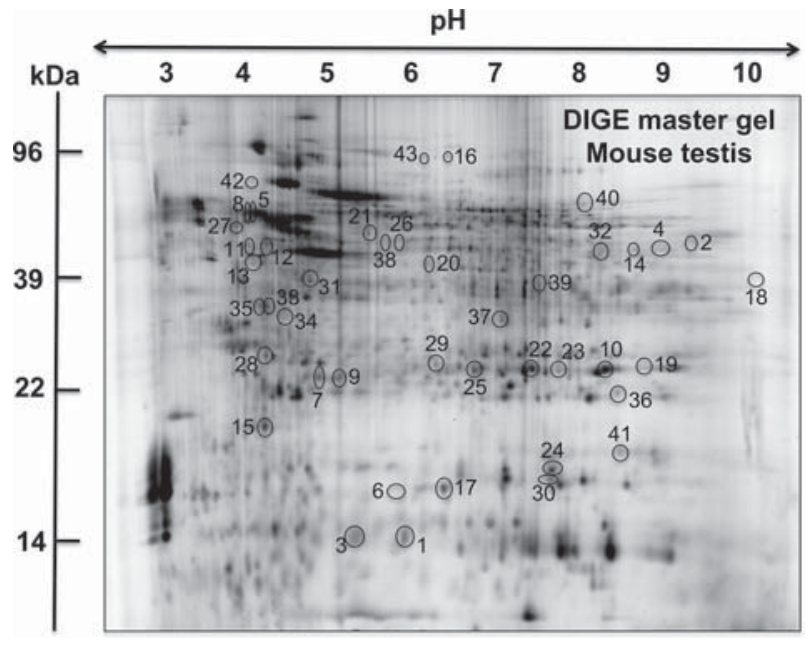

Figure 4. Fluorescence DIGE analysis of WR testis tissue. Shown is a CyDye-labelled master gel of testis extracts from the WR mouse model of globozoospermia, covering the $\mathrm{pH}$ 3-10 range. Protein spots with a changed concentration in WR testis preparations are marked by circles and are numbered 1 to 43 . See Table 2 for a detailed listing of protein species with a changed abundance in WR testis. The $\mathrm{pH}$ values of the first dimension gel system and molecular mass standards (in kilodalton) of the second dimension are indicated on the top and on the left of the panels, respectively.

spot 6). The proteomic identification of the 43 altered protein spots is shown in Table 2 and lists spot number, protein name, MASCOT score, international accession number, number of matched peptide sequences, percentage sequence coverage, $\mathrm{pI}$ value, molecular mass, fold change, ANOVA score and sequence information. The concentration of 35 proteins (spots 1-35) was reduced and 8 proteins (spots 36-43) were increased in WR testis. Changes were relatively moderate, whereby a twofold or higher alteration in abundance was evident for only four testis-associated proteins.

The highest increase of 1.8-fold was shown for two HSPs of apparent 70 and $90 \mathrm{kDa}$ (spots 42,43 ). The other proteins with an elevated concentration were identified as phospholipid hydroxide GSH peroxidase (spot 41), alpha-actin (spots 38, 40), aldolase reductase (spot 39), VDAC2 (spot 37) and peroxiredoxin (spot 36). In contrast, the highest decrease of 2.4-fold was found for fatty acid binding protein FABP3 (spot 1). A reduced concentration was also shown for acetyl-CoA acetyltransferase (spots 2, 4), beta-galactoside binding protein (spot 3), tubulin (spots 5,8), spermatid-specific protein (spot 6), huntingtin-interacting protein-2 (spot 7), PKCq-interacting protein PICOT (spot 9), GST (spots 10, 19, 23, 25), vimentin (spots 11, 27), protein phosphatase (spot 12), the 40 -kDa protein (spot 13), ATP synthase (spot 14), urinary protein types 2 and 8 (spot 15), Alix protein (spot 16), Cu/Zn SOD (spot 17), heterogenous nuclear ribonucleo-protein A2/B1 (spot 18), DnaJ protein (spots 20,29), selenide water dikinase (spot 21), flavin reductase (spot 22), nucleoside diphosphate kinase (spot 24), ornithine amino-transferase (spot 26), ubiqui- tin C-terminal hydrolase (spot 28), cofilin (spot 30), SUMOactivating enzyme (spot 31), isocitrate dehydrogenase (spot 32), annexin (spots 33, 35) and coatomer (spot 34). The identification of specific protein isoforms being present in more than one 2D spot is probably due to differences in PTMs, such as varying degrees of phosphorylation.

\subsection{Confirmation of changed protein concentrations by immunoblotting}

Immunoblotting was used to verify key findings from the proteomic screening of WR versus WT testis (Figs. 5 and 6). Although the overall protein band pattern in silver-stained 1D gels was comparable between mutant and normal preparations (Fig. 5A), the decoration of blotted proteins with specific antibodies to testis-associated components revealed distinct changes in their concentration (Figs. 5B-F and $6 \mathrm{~A}-\mathrm{E}$ ). The reduced concentration of the FABP3 isoform of the protein family of fatty acid binding proteins (Figs. 5B and 6A), the mitochondrial enzyme ATP synthase (Figs. 5C and $6 \mathrm{~B}$ ) and SOD (Figs. 5D and 6C) in WR testis was confirmed by immunoblotting. Potential changes in VDAC were not found to be significant (not shown). In contrast, the elevated concentration of the molecular chaperones Hsp70 and Hsp90 in WR testis was demonstrated by immunoblot analysis (Figs. 5E and $\mathrm{F}$ and $6 \mathrm{D}$ and $\mathrm{E}$ ).

\subsection{Summary of protein classes with a changed concentration in WR testis and protein interaction analysis}

An overview of changes in distinct classes of proteins, as revealed by MS-based proteomics, is given in the graphical presentation of Fig. 7. Proteins associated with the cytoskeleton, metabolism, stress response and other enzymatic activities of testis tissue are represented. The graph summarises the relative concentrations WR/WT of identified testicular proteins. Increased proteins and decreased proteins are shown in the upper and lower part of the graph, respectively. Twodimensional landmark protein spots with an unchanged concentration are listed on the 0/1.0 horizontal line. Solid circles mark protein species that have been identified by MS analysis and a rhombus marks proteins of which concentration changes have been additionally verified by immunoblotting. Application of the PANTHER database of protein families [51] resulted in the cataloguing of molecular functions of the identified WR proteins with a changed abundance as follows: transporter activity (4.5\%), antioxidant activity (4.5\%), binding activity $(18.2 \%)$, catalytic activity $(45.5 \%)$, enzyme regulator activity $(4.5 \%)$, ion channel activity $(9.1 \%)$, receptor activity (4.5\%) and structural molecule activity (9.1\%). Data are shown in Supporting Information Fig. 1.

Following the identification of proteins with a changed abundance in WR testis, the existence of potential protein 
Table 2. 2D-DIGE identified proteins with a changed abundance in WR testis relative to WT

\begin{tabular}{|c|c|c|c|c|c|c|c|c|c|}
\hline $\begin{array}{l}\text { Spot } \\
\text { no. }\end{array}$ & Protein name & $\begin{array}{l}\text { MASCOT } \\
\text { score }\end{array}$ & Accession no. & $\begin{array}{l}\text { Peptides } \\
\text { matched }\end{array}$ & $\begin{array}{l}\text { Coverage } \\
(\%)\end{array}$ & $\mathrm{p} /$ & $\begin{array}{l}\text { Molecular } \\
\text { mass (kDa) }\end{array}$ & $\begin{array}{l}\text { Relative } \\
\text { concentration } \\
\text { WR/WT }\end{array}$ & ANOVA \\
\hline 1 & $\begin{array}{l}\text { Fatty acid binding protein } \\
\text { FABP3, testis }\end{array}$ & 344 & gi|6753810 & 7 & 60 & 6.11 & 14810 & 0.42 & 0.004 \\
\hline 2 & $\begin{array}{l}\text { Acetyl-coenzyme A } \\
\text { acyltransferase } 2\end{array}$ & 152 & gi|148677571 & 3 & 24 & 8.48 & 25618 & 0.46 & 0.003 \\
\hline 3 & $\begin{array}{l}\text { Beta-galactoside binding } \\
\text { protein }\end{array}$ & 158 & gi|193442 & 4 & 37 & 5.32 & 15144 & 0.48 & 1.03E-04 \\
\hline 4 & Acetyl-CoA acetyltransferase & 292 & gi|21450129 & 7 & 22 & 8.71 & 45135 & 0.50 & 0.004 \\
\hline 5 & Tubulin, beta $2 \mathrm{C}$ & 258 & gi|1354268 & 12 & 35 & 4.79 & 50247 & 0.56 & 8.07E-04 \\
\hline 6 & Spermatid-specific protein & 94 & gi|556310 & 5 & 33 & 10.36 & 15099 & 0.56 & 0.011 \\
\hline 7 & $\begin{array}{l}\text { Huntingtin-interacting } \\
\text { protein-2 }\end{array}$ & 221 & gi|2897818 & 8 & 47 & 5.33 & 22505 & 0.59 & 9.79E-04 \\
\hline 8 & Tubulin, alpha-3 chain & 324 & gi|6678465 & 6 & 18 & 4.97 & 50624 & 0.59 & 0.002 \\
\hline 9 & $\begin{array}{l}\text { PKCq-interacting protein } \\
\text { PICOT }\end{array}$ & 104 & gi|6840949 & 4 & 14 & 5.42 & 38048 & 0.59 & 6.00E-03 \\
\hline 10 & GST Mu 2 & 267 & gi|6680121 & 16 & 66 & 6.9 & 25874 & 0.59 & $9.00 \mathrm{E}-03$ \\
\hline 11 & Vimentin & 117 & gi|2078001 & 15 & 36 & 4.96 & 51591 & 0.63 & 0.006 \\
\hline 12 & $\begin{array}{r}\text { Protein phosphatase } 1 \\
\text { regulatory subunit } 7\end{array}$ & 136 & gi|12963569 & 6 & 26 & 4.85 & 41382 & 0.63 & 1.10E-02 \\
\hline 13 & Protein 40 kDa & 156 & gi|226005 & 10 & 41 & 4.8 & 32848 & 0.63 & 0.014 \\
\hline 14 & ATP synthase, subunit alpha & 107 & gi|6680748 & 5 & 13 & 9.22 & 59832 & 0.67 & 3.53E-04 \\
\hline 15 & $\begin{array}{l}\text { Major urinary proteins } 11 \\
\text { and } 8\end{array}$ & 113 & gi|127531 & 3 & 23 & 4.85 & 17723 & 0.67 & 0.001 \\
\hline 16 & Alix protein & 82 & gi|3550456 & 6 & 9 & 6.15 & 96530 & 0.67 & 3.00E-03 \\
\hline 17 & $\mathrm{Cu} / \mathrm{Zn} \mathrm{SOD}$ & 171 & gi|226471 & 4 & 45 & 6.03 & 15926 & 0.67 & 0.007 \\
\hline 18 & $\begin{array}{l}\text { Heterogenous nuclear } \\
\text { ribonucleoprotein A2/B1 }\end{array}$ & 321 & gi|3329498 & 15 & 46 & 8.67 & 36029 & 0.67 & $9.00 \mathrm{E}-03$ \\
\hline 19 & GST Mu 1 & 163 & gi|6754084 & 13 & 47 & 7.71 & 26069 & 0.67 & 0.01 \\
\hline 20 & $\begin{array}{l}\text { DnaJ homolog subfamily B } \\
\text { member } 11 \text { precursor }\end{array}$ & 430 & gi|110625998 & 8 & 26 & 5.92 & 40820 & 0.71 & 1.10E-02 \\
\hline 21 & Selenide, water dikinase 2 & 119 & gi|15011843 & 4 & 21 & 5.75 & 48210 & 0.71 & 0.012 \\
\hline 22 & Flavin reductase (NADPH) & 71 & gi|21450325 & 3 & 18 & 6.49 & 22299 & 0.71 & $1.20 \mathrm{E}-02$ \\
\hline 23 & GST Mu 2 & 81 & gi|6680121 & 2 & 32 & 6.9 & 25700 & 0.77 & 4.27E-04 \\
\hline 24 & $\begin{array}{l}\text { Nucleoside diphosphate } \\
\text { kinase B }\end{array}$ & 287 & gi|6679078 & 7 & 50 & 6.97 & 17468 & 0.77 & 1.00E-03 \\
\hline 25 & GST Mu 1 & 409 & gi|6754084 & 7 & 37 & 7.71 & 26069 & 0.77 & 8.00E-03 \\
\hline 26 & $\begin{array}{l}\text { Ornithine aminotransferase, } \\
\text { mitochondrial precursor }\end{array}$ & 234 & gi|8393866 & 4 & 22 & 6.19 & 48324 & 0.77 & $9.00 \mathrm{E}-03$ \\
\hline 27 & Vimentin & 66 & gi|2078001 & 8 & 19 & 4.96 & 51591 & 0.77 & $1.00 \mathrm{E}-02$ \\
\hline 28 & $\begin{array}{l}\text { Ubiquitin C-terminal } \\
\text { hydrolase L3 }\end{array}$ & 113 & gi|7578956 & 6 & 32 & 5.08 & 26336 & 0.77 & 1.30E-02 \\
\hline 29 & DnaJ protein homolog 3 & 87 & gi|6831566 & 2 & 13 & 5.91 & 26662 & 0.83 & $1.00 \mathrm{E}-03$ \\
\hline 30 & Cofilin-1 & 120 & gi|6680924 & 2 & 15 & 8.22 & 18780 & 0.83 & 2.00E-03 \\
\hline 31 & $\begin{array}{l}\text { SUMO-activating enzyme } \\
\text { subunit } 1\end{array}$ & 162 & gi|9790247 & 12 & 41 & 5.24 & 39060 & 0.83 & $9.00 \mathrm{E}-03$ \\
\hline 32 & $\begin{array}{l}\text { NADP-dependent isocitrate } \\
\text { dehydrogenase }\end{array}$ & 157 & gi|3641400 & 10 & 28 & 6.48 & 47036 & 0.83 & 1.30E-02 \\
\hline 33 & Annexin A5 & 206 & gi|6753060 & 10 & 36 & 4.83 & 35788 & 0.83 & $1.40 \mathrm{E}-02$ \\
\hline 34 & Coatomer subunit epsilon & 127 & gi|10946972 & 4 & 19 & 4.94 & 34777 & 0.83 & $1.50 \mathrm{E}-02$ \\
\hline 35 & Annexin A5 & 215 & gi|6753060 & 3 & 36 & 4.83 & 35730 & 0.91 & $1.50 \mathrm{E}-02$ \\
\hline 36 & Peroxiredoxin-1 & 163 & gi|6754976 & 5 & 28 & 8.26 & 22394 & 1.2 & 8.00E-03 \\
\hline 37 & VDAC2 & 263 & gi|6755965 & 6 & 24 & 7.44 & 32351 & 1.3 & $1.20 \mathrm{E}-02$ \\
\hline 38 & Actin, alpha & 86 & gi|387090 & 4 & 18 & 5.23 & 41758 & 1.3 & 3.00E-03 \\
\hline 39 & Aldose reductase & 225 & gi|3046247 & 13 & 40 & 6.71 & 36043 & 1.4 & $9.00 \mathrm{E}-03$ \\
\hline 40 & Actin, alpha & 49 & gi|387090 & 4 & 20 & 5.23 & 42048 & 1.4 & 2.00E-03 \\
\hline 41 & $\begin{array}{l}\text { Phospholipid hydroperoxide } \\
\text { glutathione peroxidase }\end{array}$ & 161 & gi|3114602 & 5 & 31 & 8.34 & 20032 & 1.5 & $1.00 \mathrm{E}-03$ \\
\hline 42 & $\begin{array}{l}\text { Heat shock related } 70-k D a \\
\text { protein } 2\end{array}$ & 140 & gi|31560686 & 13 & 26 & 5.51 & 69889 & 1.8 & $1.40 \mathrm{E}-02$ \\
\hline 43 & Hsp90-alpha & 72 & gi|6754254 & 2 & 3 & 4.93 & 85141 & 1.8 & 6.00E-03 \\
\hline
\end{tabular}


A Silver

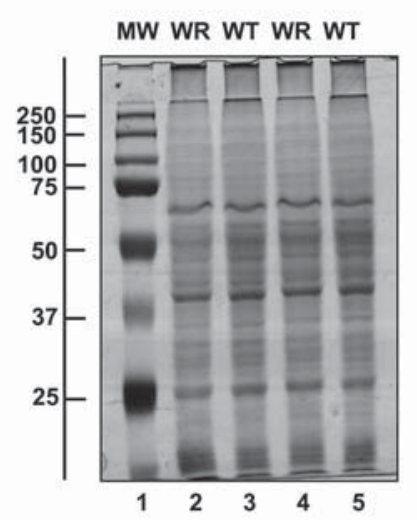

D SOD
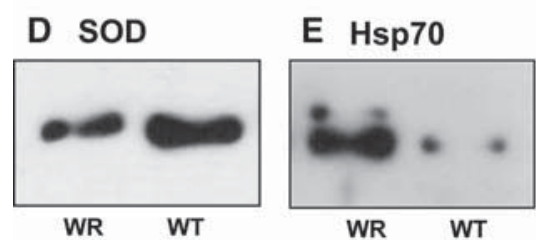

B

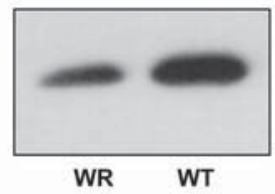

C ATP synthase

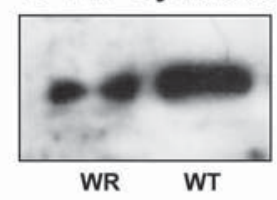

F Hsp90

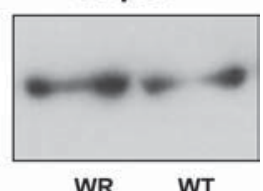

Figure 5. Immunoblot analysis of WR versus WT testis. Shown is a silver-stained 1D gel of preparations from WR (lanes 2 and 4) and WT (lanes 3 and 5) testis. Lane 1 shows molecular mass standards with their values in kilodalton on the left side of the panel (A). Representative immunoblots with an expanded view of immuno-decorated bands are shown in panels $B$ to $F$ and are labelled with antibodies to the FABP3 testis isoform of fatty acid binding protein, ATP synthase, SOD and the molecular chaperones Hsp70 and Hsp90, respectively. Lanes 1 and 2 represent mutant WR testis versus normal WT preparations, respectively.

interactions was evaluated with the help of the IntAct molecular interaction database [50] and the STRING database of direct physical and indirect functional protein interactions [49]. According to the comparison of the proteins listed in Table 2 and published protein interactions stored in the IntAct database, the only major interaction pattern was predicted to exist between huntingtin-interacting protein- 2 and nucleoside diphosphate kinase B. The protein interaction analysis is listed in Supporting Information Table 1. Application of the STRING database of direct physical and indirect functional protein interactions [49] resulted in a more complex interaction map, shown in Fig. 8. Strong interactions were predicted to exist between the mitochondrial proteins VDAC2, ATP synthase and acetyl-CoA acyltransferase. Additional interactions through the ATP synthase hub were shown to occur with ornithine aminotransferase, heterogeneous nuclear ribonucleoprotein and coatomer protein. The bioinformatics analysis also demonstrated a clear association between the molecular chaperones Hsp70 and Hsp90, as well as the DnaJ protein, confirming their related roles in the cellular stress response. Potential connections were highlighted between SOD, GST and peroxiredoxin and their role in antioxidant defence, biotransformation and redox regulation of testis tissue. Weak interactions are predicted to exist
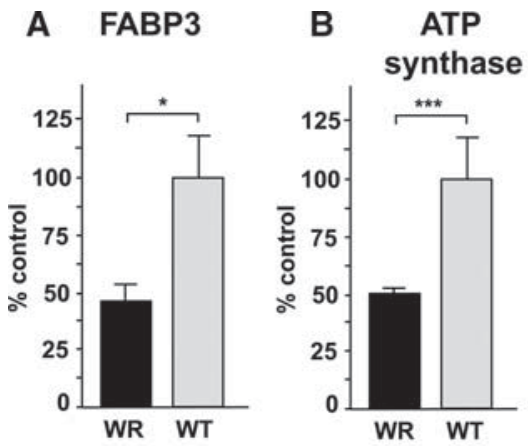

C SOD

D Hsp70
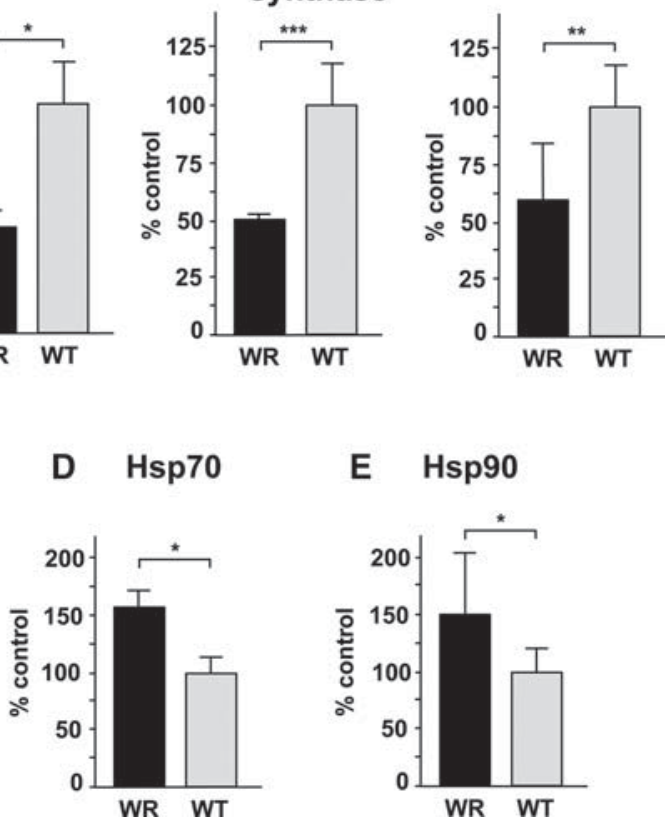

E Hsp90

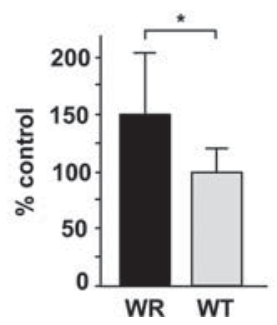

Figure 6. Quantitative analysis of selected testis proteins. The graphical presentation of the statistical analysis of immunoblotting of the FABP3 testis isoform of fatty acid binding protein, ATP synthase, SOD and the molecular chaperones Hsp70 and Hsp90 is shown in panels $A$ to $\mathrm{E}$, respectively (Student's $t$-test, unpaired; $n=5$; ${ }^{*} p<0.05$; ${ }^{*} p<0.01$; ${ }^{*} p<0.001$ ).

between the intermediate filament component vimentin and annexin.

\section{Discussion}

Functional VPS54 is indispensable for the prenatal development of the mouse, as shown by knockout experiments [6]. Thus, the wr missense mutation appears to be a relatively mild allele that causes both the neurological and the testis phenotype of the WR mouse as has been shown by transgenic rescue [6]. Using X-ray and biochemical analysis, Pérez-Victoria et al. [9] elucidated the effect of the VPS54 L967Q hydrophobic-tohydrophilic amino acid replacement, which destabilizes the conformation of VPS54 and renders it temperature-sensitive. This in turn leads to a partial proteolytic degradation of the misfolded VPS54 polypeptide at the body temperature of the mouse. Thus, VPS54 might have been expected among the proteins with a lowered concentration in WR tissue. However, VPS54 was not identified in any spots on the analytical 2D gels used in this study. Thermal denaturation and proteolytic degradation may be less pronounced in the testis due to a lower temperature than in the trunk. This might explain why the testis phenotype of WR mice is suppressed in certain mouse strains whereas the neurological phenotype is not (T. Schmitt-John and A. Mussmann, unpublished 


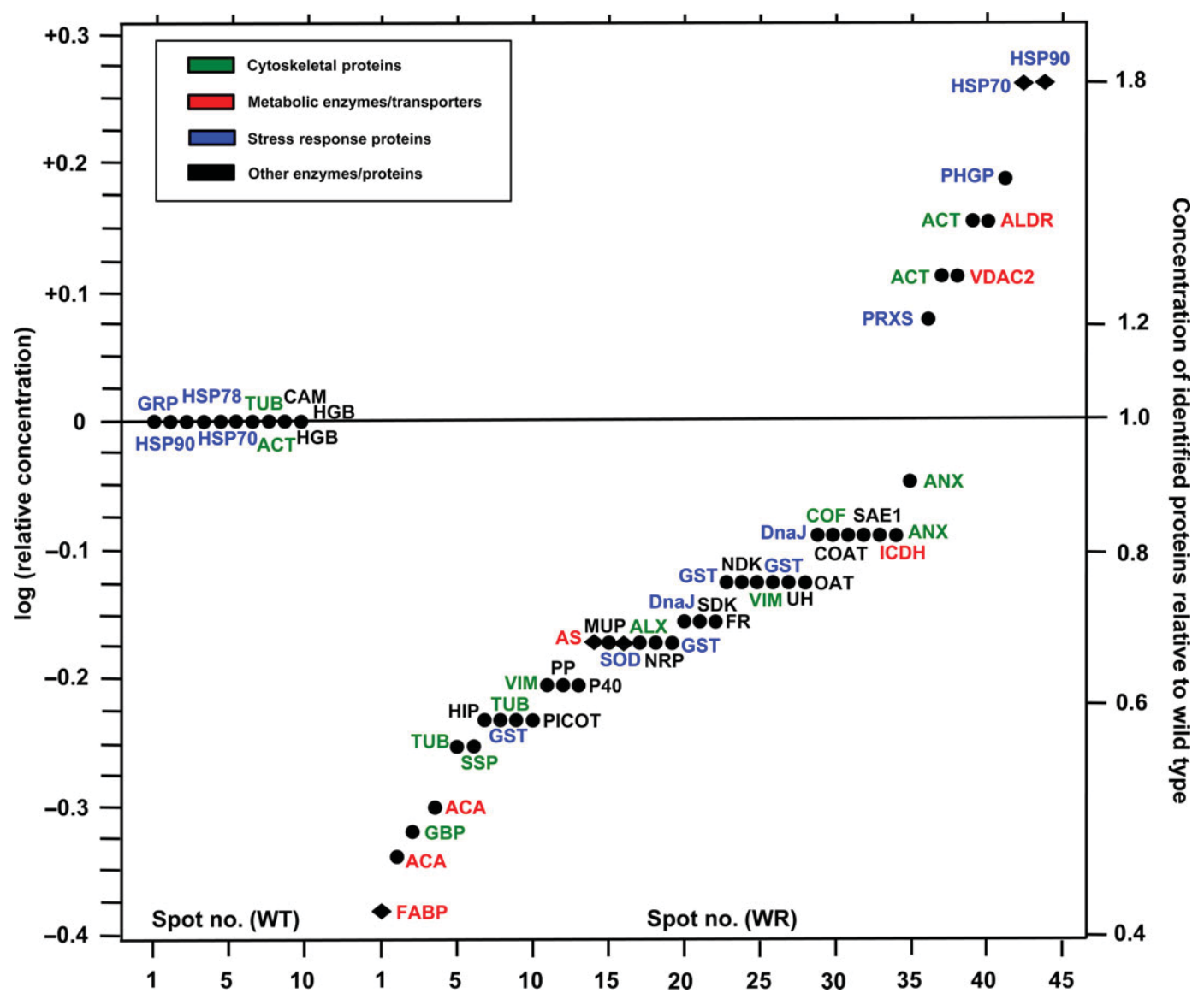

Figure 7. Overview of alterations in WR testicular tissue versus WT control. The graph shows the relative concentrations WR/WT of testicular polypeptides as revealed by MS-based proteomics. Increased versus decreased proteins are shown in the upper and lower part of the graph, respectively, and unchanged proteins are listed on the 0/1.0 horizontal line. Proteins belonging to the cytoskeleton, metabolism, stress response and other enzymatic activities are marked by green, red, blue and black symbols, respectively. Protein species that have been identified by MS analysis are marked by a solid circle and proteins of which concentration changes have been additionally verified by immunoblotting are marked by a rhombus. ACA, acetyl-CoA acyltransferase; ACT, actin; ALDR, aldose reductase; ALX, Alix protein; ANX, annexin; AS, ATP synthase; CAM, calmodulin; COAT, coatomer; COF, cofilin; DnaJ, DnaJ homolog protein; FABP3, fatty acid binding protein isoform 3; FR, flavin reductase; GBP, galactoside-binding protein; GRP, endoplasmin GRP94; HGB, haemoglobin; HIP, huntingtininteracting protein; Hsp70, heat shock related 70-kDa protein 2; Hsp78, 78-kDa glucose-regulated protein; Hsp90, HSP Hsp90-alpha; ICDH, isocitrate dehydrogenase; MUP, major urinary proteins; SOD, superoxide dismutase; NDK, nucleoside diphosphate kinase; NRP, nuclear ribonucleoprotein; OAT, ornithine aminotransferase; P40, protein $40 \mathrm{kDa}$; PHGP, phospholipid hydroperoxide glutathione peroxidase; PICOT, PKCq-interacting protein; PRXS, peroxiredoxin; PP, protein phosphatase; SAE1, SUMO-activating enzyme subunit 1; SDK, selenide, water dikinase; SSP, spermatid-specific protein; TUB, tubulin; UH, ubiquitin hydrolase; VDAC2, voltage-dependent anion-selective channel protein 2; VIM, vimentin. The presentation of specific protein isoforms by multiple 2D spots is probably due to differences in PTMs, such as varying degrees of phosphorylation.

observation). Indeed, Paiardi et al. [10] were able to stain WR testis with an unspecified antibody directed against VPS54, showing an intensity comparable to labelling of the WT, whereas Pérez-Victoria et al. [9] found a strongly reduced signal in central nervous system and liver extracts from WR mice, as compared to WT using immunoblotting. In the light of these findings, together with the results of a detailed electron microscopic analysis shown here, one would expect rather moderate changes in the protein pattern of WR testis.

The main findings from the proteomic profiling of WR testis revealed altered concentrations of proteins associated with metabolite transport, fatty acid metabolism, cellular interactions, microtubule assembly and the cellular stress response. In addition, minor changes were observed for proteins involved in various cellular activities, including cell redox homeostasis, biotransformation, cytoskeleton formation, PTMs, detoxification, and metabolism. The proteomic analysis of WR testis revealed an increase in two critical HSPs, i.e. Hsp70-2 and Hsp90 $\alpha$ [52]. The main functions of the Hsp70 and Hsp90 class of molecular chaperones involve the facilitation of protein folding, the maintenance of proteome integrity and the regulation of protein homeostasis [53]. The bioinformatics analysis using the STRING database [49] suggests close interactions between 


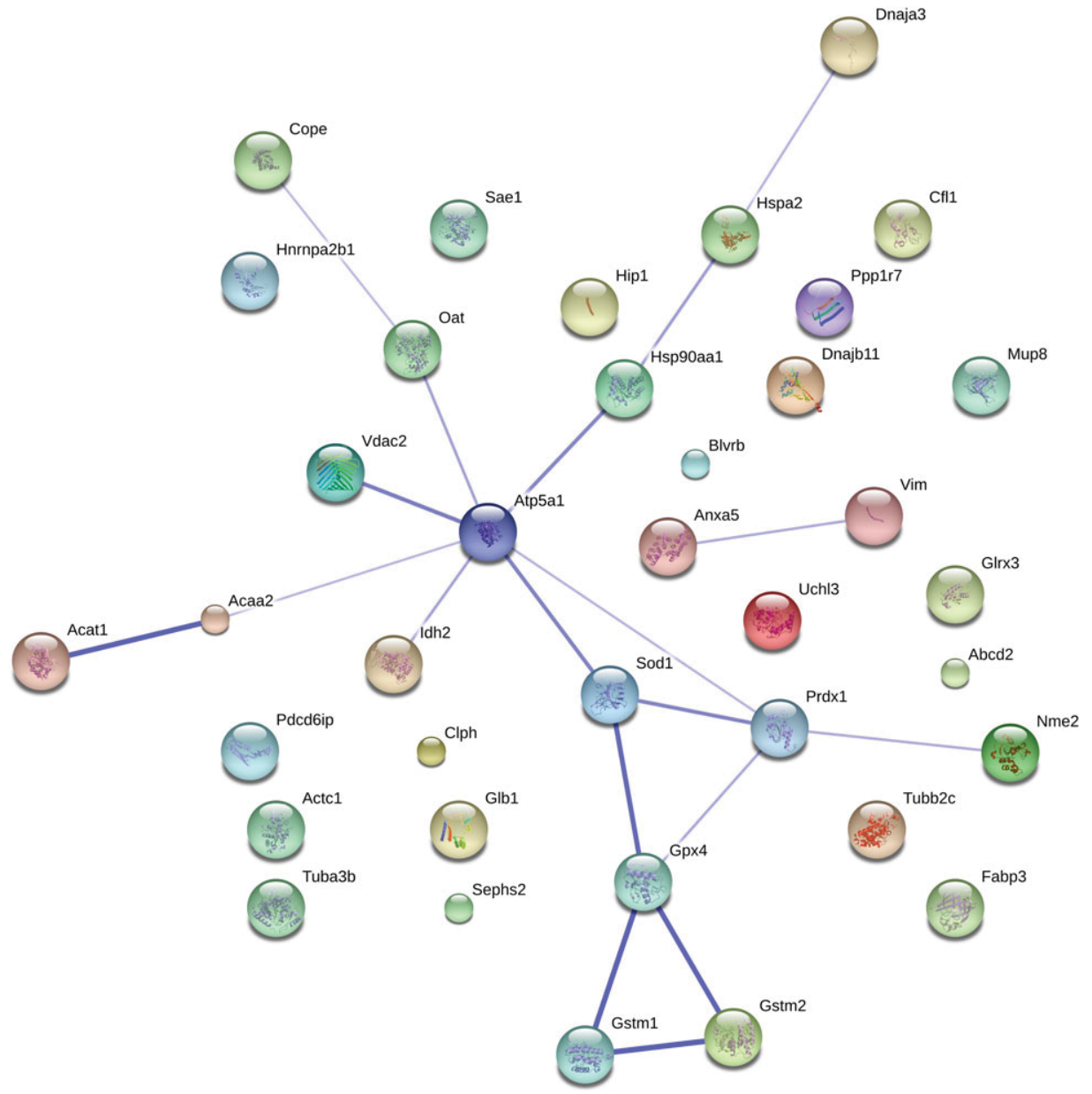

Figure 8. Protein interaction map of WR testis proteins. Shown is a protein interaction map generated with the STRING database (version 9.1) of known and predicted protein associations that include direct physical and indirect functional protein linkages. The analysis was carried out with proteins that exhibited a changed abundance in WR testis (Table 2). The prediction of protein interactions is based on published data with respect to neighbourhood, gene fusion, cooccurrence, co-expression, experiments, databases, text-mining and homology data [49]. the two stress proteins and essential cooperation during chaperone-mediated protein folding processes in order to maintain cellular proteostasis. Both HSPs are believed to play major roles during spermatogenesis [54-56]. Hsp70-2 was shown to represent a protein factor that is crucial for the successful completion of meiosis in mouse spermatocytes [57]. Disruption of the Hsp70-2 gene results in male infertility due to failed meiosis and germ cell apoptosis $[58,59]$. Thus, the testis-specific HSP Hsp70-2 appears to have an essential chaperone function during the meiotic phase of spermatogenesis [57]. A proteomic and immuno-histochemical survey of developmental changes in HSPs from porcine testis has demonstrated a differential effect on molecular chaperones, whereby the Hsp90 $\alpha$ isoform was shown to increase after sexual maturation [60]. Hence, the increased abundance of Hsp70-2 and Hsp90 $\alpha$ in WR testis suggests that these essential molecular chaperones are upregulated to counteract detrimental protein aggregation in VPS54-deficient tissues.

The most significant decrease in a specific protein was shown to be the approximately twofold reduction of the FABP3 isoform of fatty acid binding protein. Both, densitometric scanning of fluorescent 2D gels and immunoblotting agreed that this metabolite transporter is severely affected in WR testis tissue. Fatty acid binding proteins belong to the superfamily of lipid-binding proteins and are widely distributed throughout the body [61]. Their primary function is the regulation of fatty acid uptake and intracellular transportation of this essential energy-rich biomolecule. Various types of fatty acid binding proteins have been shown to play a role during spermatogenesis [62-64]. The major isoform FABP3 exists in heart, muscle, kidney and testis [65]. The reduction of FABP3 in WR testes suggests that the loss of VPS54 results in downstream effects on key metabolic pathways and causes abnormal fatty acid utilization. Since the enzyme acetyl-CoA acetyltransferase was also shown to be reduced, the fatty acid oxidation pathway appears to be impaired in WR testes. Interestingly, the bioinformatics analysis using the STRING database [49] suggests ATP synthase as a major hub and close associations with other metabolic enzymes and mitochondrial proteins. This agrees with the idea that bioenergetic abnormalities affecting oxidative metabolism might be involved in impaired spermatogenesis.

Microtubules and intermediate filaments play an important role during spermatogenesis [66]. The proteomic 
screening of WR testis preparations revealed reduced levels of $\alpha$-tubulin, $\beta$-tubulin, beta-galactoside binding protein and vimentin. These changes could potentially be due to an abnormal cytoskeletal organization in WR testis or these variations in cytoskeletal protein levels might reflect an altered cell composition of the WR testis as compared to WT. Concentration changes in other potentially interesting novel marker candidates were relatively minor and their pathobiochemical relevance therefore difficult to judge. Proteins included the spermatid-specific histone $\mathrm{H} 2 \mathrm{~b}$ protein [67], an ubiquitin-conjugating enzyme named huntingtin-interacting protein-2 [68], the sperm-specific HSP DnaJ [69, 70], and a variety of enzymes involved in metabolism, detoxification and biotransformation.

In conclusion, the proteomic analysis of the WR testis presented here supports the general idea that global changes in protein concentrations are moderate despite the dramatic morphological abnormalities in spermatogenesis. In conjunction with the results from the analysis of inter-strain crosses, the novel proteomic findings indicate that the testis phenotype of the VPS54 L967Q missense mutation is less penetrant than the neurological phenotype. However, impaired spermatogenesis in the WR mouse is associated with a generally perturbed protein expression pattern. Several interesting new marker proteins with a changed concentration were identified, including the FABP3 isoform of fatty acid binding protein, the molecular chaperones Hsp70-2 and $\mathrm{Hsp} 90 \alpha$, and various proteins associated with cell-cell interactions, microtubule assembly, cellular homeostasis, biotransformation, cytoskeleton formation, detoxification and bioenergetics. In the long-term, the newly identified proteins from the testis proteome may be useful candidates for advancing the molecular analysis of globozoospermia.

Research was funded by project grants from the Irish Health Research Board, the PRTLI5 BioAT programme of the Irish Higher Education Authority and Fonds der Chemischen Industrie. The Deutscher Akademischer Austauschdienst and the Irish Higher Education Authority supported several laboratory visits of the Maynooth team in Germany and Denmark.

The authors have declared no conflict of interest.

\section{References}

[1] Duchen, L. W., Strich, S. J., A hereditary motor neuron disease with progressive denervation of muscle in the mouse: the mutant 'wobbler'. J. Neurol. Neurosurg. Psychiatry 1968 $31,535-542$.

[2] Moser, J. M., Bigini, P., Schmitt-John, T., The wobbler mouse, an ALS animal model. Mol. Genet. Genomics 2013, 288, 207-229.

[3] Leestma, J. E., Sepsenwol, S., Sperm tail axoneme alterations in the Wobbler mouse. J. Reprod. Fertil. 1980, 58, 267-270.
[4] Heimann, P., Laage, S., Jockusch, H., Defect of sperm assembly in a neurological mutant of the mouse, wobbler (WR). Differentiation 1991, 47, 77-83.

[5] Kaupmann, K., Simon-Chazottes, D., Guénet, J. L., Jockusch, $\mathrm{H}$. et al., Wobbler, a mutation affecting motoneuron survival and gonadal functions in the mouse, maps to proximal chromosome 11. Genomics 1992, 13, 39-43.

[6] Schmitt-John, T., Drepper, C., Mussmann, A., Hahn, P. et al., Mutation of Vps54 causes motor neuron disease and defective spermiogenesis in the wobbler mouse. Nat. Genet. 2005, 37, 1213-1215.

[7] Bonifacino, J. S, Hierro, A., Transport according to GARP: receiving retrograde cargo at the trans-Golgi network. Trends Cell Biol. 2011, 21, 159-167.

[8] Meisler, M. H., Russ, C., Montgomery, K. T., Greenway, M. et al., Evaluation of the Golgi trafficking protein VPS54 (wobbler) as a candidate for ALS. Amyotroph. Lateral Scler. 2008, 9, 141-148.

[9] Pérez-Victoria, F. J., Abascal-Palacios, G., Tascón, I., Kajava, A. et al., Structural basis for the wobbler mouse neurodegenerative disorder caused by mutation in the Vps54 subunit of the GARP complex. Proc. Natl. Acad. Sci. USA 2010, 107, 12860-12865.

[10] Paiardi, C., Pasini, M. E., Gioria, M., Berruti, G., Failure of acrosome formation and globozoospermia in the wobbler mouse, a Vps54 spontaneous recessive mutant. Spermatogenesis 2011, 1, 52-62.

[11] Dam, A. H., Feenstra, I., Westphal, J. R., Ramos, L. et al., Globozoospermia revisited. Hum. Reprod. Update 2007, 13, 63-75.

[12] Perrin, A., Coat, C., Nguyen, M. H., Talagas, M. et al., Molecular cytogenetic and genetic aspects of globozoospermia: a review. Andrologia. 2013, 45, 1-9.

[13] Chianese, R., Scarpa, D., Berruti, G., Cobellis, G. et al., Expression and localization of the deubiquitinating enzyme mUBPy in wobbler mouse testis during spermiogenesis. Gen. Comp. Endocrinol. 2010, 166, 289-295.

[14] Heytens, E., Schmitt-John, T., Moser, J. M., Jensen, N. M. et al., Reduced fertilization after ICSI and abnormal phospholipase $C$ zeta presence in spermatozoa from the wobbler mouse. Reprod. Biomed. Online 2010, 21, 742-749.

[15] Oatley, J. M., Brinster, R. L., The germline stem cell niche unit in mammalian testes. Physiol. Rev. 2012, 92, 577-595.

[16] Oliva, R., de Mateo, S., Castillo, J., Azpiazu, R. et al., Methodological advances in sperm proteomics. Hum. Fertil. (Camb.) 2010, 13, 263-267.

[17] Oliva, R., de Mateo, S., Estanyol, J. M., Sperm cell proteomics. Proteomics 2009, 9, 1004-1017.

[18] du Plessis, S. S., Kashou, A. H., Benjamin, D. J., Yadav, S. P., Agarwal, A., Proteomics: a subcellular look at spermatozoa. Reprod. Biol. Endocrinol. 2011, 9, 36.

[19] Baker, M. A., The 'omics revolution and our understanding of sperm cell biology. Asian J. Androl. 2011, 13, 6-10.

[20] Chocu, S., Calvel, P., Rolland, A. D., Pineau, C., Spermatogenesis in mammals: proteomic insights. Syst. Biol. Reprod. Med. 2012, 58, 179-190. 
[21] Govindaraju, A., Dogan, S., Rodriguez-Osorio, N., Grant, K. et al., Delivering value from sperm proteomics for fertility. Cell Tissue Res. 2012, 349, 783-793.

[22] Johnston, D. S., Wooters, J., Kopf, G. S., Qiu, Y., Roberts, K. P., Analysis of the human sperm proteome. Ann. NY Acad. Sci. 2005, 1061, 190-202.

[23] Martínez-Heredia, J., Estanyol, J. M., Ballescà, J. L., Oliva, R., Proteomic identification of human sperm proteins. Proteomics 2006, 6, 4356-4369.

[24] Wang, G., Guo, Y., Zhou, T., Shi, X. et al., In-depth proteomic analysis of the human sperm reveals complex protein compositions. J. Proteomics 2013, 79, 114-122.

[25] Baker, M. A., Hetherington, L., Reeves, G. M., Aitken, R. J., The mouse sperm proteome characterized via IPG strip prefractionation and LC-MS/MS identification. Proteomics 2008, 8, 1720-1730.

[26] Baker, M. A., Hetherington, L., Reeves, G., Müller, J., Aitken, R. J., The rat sperm proteome characterized via IPG strip prefractionation and LC-MS/MS identification. Proteomics 2008, 8, 2312-2321.

[27] Baker, M. A., Naumovski, N., Hetherington, L., Weinberg, A. et al., Head and flagella sub-compartmental proteomic analysis of human spermatozoa. Proteomics 2013, 13, 61-74.

[28] Brewis, I. A., Gadella, B. M., Sperm surface proteomics: from protein lists to biological function. Mol. Hum. Reprod. 2010, $16,68-79$

[29] Dacheux, J. L., Belleannée, C., Guyonnet, B., Labas, V. et al., The contribution of proteomics to understanding epididymal maturation of mammalian spermatozoa. Syst. Biol. Reprod. Med. 2012, 58, 197-210.

[30] Ficarro, S., Chertihin, O., Westbrook, V. A., White, F. et al., Phosphoproteome analysis of capacitated human sperm. Evidence of tyrosine phosphorylation of a kinase-anchoring protein 3 and valosin-containing protein/p97 during capacitation. J. Biol. Chem. 2003, 278, 11579-11589.

[31] Secciani, F., Bianchi, L., Ermini, L., Cianti, R. et al., Protein profile of capacitated versus ejaculated human sperm. J. Proteome Res. 2009, 8, 3377-3389.

[32] Baker, M. A., Reeves, G., Hetherington, L., Aitken, R. J., Analysis of proteomic changes associated with sperm capacitation through the combined use of IPG-strip pre-fractionation followed by RP chromatography LC-MS/MS analysis. Proteomics 2010, 10, 482-495.

[33] Baker, M. A., Nixon, B., Naumovski, N., Aitken, R. J., Proteomic insights into the maturation and capacitation of mammalian spermatozoa. Syst. Biol. Reprod. Med. 2012, 58, 211-217.

[34] Stanton, P. G., Sluka, P., Foo, C. F., Stephens, A. N. et al., Proteomic changes in rat spermatogenesis in response to in vivo androgen manipulation; impact on meiotic cells. PLoS One 2012, 7, e41718.

[35] Hamada, A., Sharma, R., du Plessis, S. S., Willard, B. et al., Two-dimensional differential in-gel electrophoresis-based proteomics of male gametes in relation to oxidative stress. Fertil. Steril. 2013, 99, 1216-1226.
[36] Porambo, J. R., Salicioni, A. M., Visconti, P. E., Platt, M. D., Sperm phosphoproteomics: historical perspectives and current methodologies. Expert Rev. Proteomics 2012, 9, 533-548.

[37] Sutovsky, P., Proteomic analysis of mammalian gametes and sperm-oocyte interactions. Soc. Reprod. Fertil. Suppl. 2009, $66,103-116$.

[38] Tomar, A. K., Saraswat, M., Chhikara, N., Kumar, S. et al., Differential proteomics of sperm: insights, challenges and future prospects. Biomark. Med. 2010, 4, 905-910.

[39] Xu, W., Hu, H., Wang, Z., Chen, X. et al., Proteomic characteristics of spermatozoa in normozoospermic patients with infertility. J. Proteomics 2012, 75, 5426-5436.

[40] Parte, P. P., Rao, P., Redij, S., Lobo, V. et al., Sperm phosphoproteome profiling by ultra performance liquid chromatography followed by data independent analysis (LC-MS(E)) reveals altered proteomic signatures in asthenozoospermia. J. Proteomics 2012, 75, 5861-5871.

[41] Milardi, D., Grande, G., Vincenzoni, F., Castagnola, M., Marana, R., Proteomics of human seminal plasma: identification of biomarker candidates for fertility and infertility and the evolution of technology. Mol. Reprod. Dev. 2013. 80, 350-357.

[42] Minden, J. S., DIGE: past and future. Methods Mol. Biol. 2012, 854, 3-8.

[43] Laage, S., Zobel, G., Jockusch, H., Astrocyte overgrowth in the brain stem and spinal cord of mice affected by spinal atrophy, wobbler. Dev. Neurosci. 1988, 10, 190-198.

[44] Bastone, A., Fumagalli, E., Bigini, P., Perini, P. et al., Proteomic profiling of cervical and lumbar spinal cord reveals potential protective mechanisms in the wobbler mouse, a model of motor neuron degeneration. J. Proteome Res. 2009, 8, 5229-5240.

[45] Zhai, J., Ström, A. L., Kilty, R., Venkatakrishnan, P. et al., Proteomic characterization of lipid raft proteins in amyotrophic lateral sclerosis mouse spinal cord. FEBS J. 2009, 276, 3308-3323.

[46] Staunton, L., Jockusch, H., Ohlendieck, K., Proteomic analysis of muscle affected by motor neuron degeneration: the wobbler mouse model of amyotrophic lateral sclerosis. Biochem. Biophys. Res. Commun. 2011, 406, 595-600.

[47] Staunton, L., Jockusch, H., Wiegand, C., Albrecht, T., Ohlendieck, K., Identification of secondary effects of hyperexcitability by proteomic profiling of myotonic mouse muscle. Mol. Biosyst. 2011, 7, 2480-2489.

[48] Doran, P., Wilton, S. D., Fletcher, S., Ohlendieck, K., Proteomic profiling of antisense-induced exon skipping reveals reversal of pathobiochemical abnormalities in dystrophic mdx diaphragm. Proteomics 2009, 9, 671-685.

[49] Franceschini, A., Szklarczyk, D., Frankild, S., Kuhn, M. et al., STRING v9.1: protein-protein interaction networks, with increased coverage and integration. Nucleic Acids Res. 2013, 41, D808-D815.

[50] Kerrien, S., Aranda, B., Breuza, L., Bridge, A. et al., The IntAct molecular interaction database in 2012. Nucleic Acids Res. 2012, 40, D841-D846. 
[51] Mi, H., Muruganujan, A., Thomas, P. D., PANTHER in 2013: modeling the evolution of gene function, and other gene attributes, in the context of phylogenetic trees. Nucleic Acids Res. 2013, 41, D377-D386.

[52] Neuer, A., Spandorfer, S. D., Giraldo, P., Jeremias, J. et al., Heat shock protein expression during gametogenesis and embryogenesis. Infect. Dis. Obstet. Gynecol. 1999, 7, 10-16.

[53] Kim, Y. E., Hipp, M. S., Bracher, A., Hayer-Hartl, M., Hartl, F. U., Molecular chaperone functions in protein folding and proteostasis. Annu. Rev. Biochem. 2013, 82, 323-355.

[54] Zakeri, Z. F., Wolgemuth, D. J., Developmental-stage-specific expression of the hsp70 gene family during differentiation of the mammalian male germ line. Mol. Cell Biol. 1987, 7 , 1791-1796.

[55] Gruppi, C. M., Zakeri, Z. F., Wolgemuth, D. J., Stage and lineage-regulated expression of two hsp90 transcripts during mouse germ cell differentiation and embryogenesis. Mol. Reprod. Dev. 1991, 28, 209-217.

[56] Dix, D. J., Hsp70 expression and function during gametogenesis. Cell Stress Chaperones 1997, 2, 73-77.

[57] Eddy, E. M., Role of heat shock protein HSP70-2 in spermatogenesis. Rev. Reprod. 1999, 4, 23-30.

[58] Dix, D. J., Allen, J. W., Collins, B. W., Mori, C. et al., Targeted gene disruption of Hsp70-2 results in failed meiosis, germ cell apoptosis, and male infertility. Proc. Natl. Acad. Sci. USA 1996, 93, 3264-3268.

[59] Dix, D. J., Rosario-Herrle, M., Gotoh, H., Mori, C. et al., Developmentally regulated expression of hsp70-2 and a hsp702/lacZ transgene during spermatogenesis. Dev. Biol. 1996, $174,310-321$

[60] Huang, S. Y., Tam, M. F., Hsu, Y. T., Lin, J. H. et al., Developmental changes of heat-shock proteins in porcine testis by a proteomic analysis. Theriogenology 2005, 64, 1940-1955.

[61] Chmurzyńska, A., The multigene family of fatty acid-binding proteins (FABPs): function, structure and polymorphism. J. Appl. Genet. 2006, 47, 39-48.
[62] Kido, T., Namiki, H., Expression of testicular fatty acidbinding protein PERF 15 during germ cell apoptosis. Dev. Growth Differ. 2000, 42, 359-366.

[63] Kido, T., Arata, S., Suzuki, R., Hosono, T. et al., The testicular fatty acid binding protein PERF15 regulates the fate of germ cells in PERF15 transgenic mice. Dev. Growth Differ. 2005 47, 15-24.

[64] Liu, R. Z., Li, X., Godbout, R., A novel fatty acid-binding protein (FABP) gene resulting from tandem gene duplication in mammals: transcription in rat retina and testis. Genomics 2008, 92, 436-445.

[65] Smathers, R. L., Petersen, D. R., The human fatty acidbinding protein family: evolutionary divergences and functions. Hum. Genomics 2011, 5, 170-191.

[66] Amlani, S., Vogl, A. W., Changes in the distribution of microtubules and intermediate filaments in mammalian Sertoli cells during spermatogenesis. Anat. Rec. 1988, 220, 143-160.

[67] Moss, S. B., Challoner, P. B., Groudine, M., Expression of a novel histone 2B during mouse spermiogenesis. Dev. Biol. $1989,133,83-92$

[68] Wilson, R. C., Hughes, R. C., Flatt, J. W., Meehan, E. J. et al., Structure of full-length ubiquitin-conjugating enzyme E2-25K (huntingtin-interacting protein 2). Acta Crystallogr. Sect. F Struct. Biol. Cryst. Commun. 2009, 65, 440-444.

[69] Boillée, S., Berruti, G., Meccariello, R., Grannec, G. et al., Early defect in the expression of mouse sperm DNAJ 1, a member of the DNAJ/heat shock protein 40 chaperone protein family, in the spinal cord of the wobbler mouse, a murine model of motoneuronal degeneration. Neuroscience 2002, 113, 825-835.

[70] Meccariello, R., Cobellis, G., Berruti, G., Junier, M. P. et al., Mouse sperm cell-specific DnaJ first homologue: an evolutionarily conserved protein for spermiogenesis. Biol. Reprod. $2002,66,1328-1335$. 